\title{
Infertility: still a largely uncovered and undertreated disease
}

\author{
Alexander M. Quaas ${ }^{1,2}$ (D) Maansi Manoj ${ }^{3}$ \\ Received: 19 April 2021 / Accepted: 20 April 2021 / Published online: 28 April 2021 \\ (C) The Author(s), under exclusive licence to Springer Science+Business Media, LLC, part of Springer Nature 2021
}

Keywords Infertility coverage $\cdot$ Access to care $\cdot$ Health disparities $\cdot$ Assisted reproductive technology

A few weeks ago, nested between countless messages inviting me to submit a manuscript to an obscure journal or attend a conference in China, I received an email out of the blue from Maansi, a 10th grader from Georgia, with an invitation to connect. The email exuded drive and enthusiasm, and despite my wife's warnings that this may be a "Nigerian prince" type of scam, I reached out to her.

During the initial conversation, Maansi explained that she was a high school student interested in women's health, and that part of her motivation to consider a career in the field of gynecology was a self-described passion for working in the fields of reproductive justice and equitable healthcare delivery. She witnessed how prompt medical assistance helped a close friend with severe Crohn's disease at a young age, giving her pause to reflect about those who are not as lucky to have access to proper healthcare. In her own words, she set out to "use her privilege to make sure that others get the treatment that they deserve."

With this backdrop, she has reached out to her community by creating a website dedicated to raising awareness of the harm of our current healthcare laws toward minorities (specifically the LGBTQ+ community) and taking a proactive stance to address cuts in healthcare funding through legislative advocacy. Her stated aim is "to close the coverage gap so that everyone has access to healthcare regardless of race, color, religion, gender, or sexual orientation."

Most reproductive endocrinology and infertility specialists originally set out to help other people when they chose their vocation or at least stated this in numerous personal statements

Alexander M. Quaas

aquaas@health.ucsd.edu

1 Division of Reproductive Endocrinology and Infertility, University of California, San Diego, CA, USA

2 Reproductive Partners San Diego, 9850 Genesee Avenue, Suite \# 800, La Jolla, San Diego, CA 92037, USA

3 Northview High School, Johns Creek, GA, USA for applications at various stages of their career. And we do help people conceive every day. Fact is the majority of people we help in the USA are white, educated, and affluent.

This is not by choice but more a matter of inequitable insurance coverage distribution: a large portion of the population is uninsured, and amongst the insured, only a small fraction have access to fertility benefits. The gap between the "haves and the have nots" has been widening for years, with a dramatic acceleration of this process during the COVID-19 pandemic [1]. Educated and wealthy employees of tech companies with special insurance add-ons enjoy access to almost limitless fertility benefits, including fertility preservation and even coverage for "add-ons" to ART services, such as the use of human growth hormone during ovarian stimulation. In contrast, tubal occlusion or severe male factor, relatively easy-tofix "bread and butter" indications for IVF, still represents a reproductive death sentence for the majority of the population devoid of access to ART coverage [2].

In this month's issue of JARG, Thakker et al. report the results of a retrospective analysis of cross-sectional data obtained from the National Survey for Family Growth (NSFG) comparing demographic characteristics of infertile women who accessed infertility services with those that did not [3]. The investigators found that on average, women with infertility who remained unevaluated had lower household incomes and lower levels of education and were more likely to be uninsured. They conclude that unevaluated infertile women represent an underserved population and point out that while ART services are increasingly utilized, the bulk of this increase consists of older women with higher levels of education, as opposed to a more uniform distribution across demographic strata. They postulate that fully mandated infertility coverage is necessary to enable expanded access to infertility care.

In 2009, the International Committee for Monitoring Assisted Reproductive Technology and the World Health Organization (WHO) defined infertility "a disease of the reproductive system." [4] Delegates at the 2017 American Medical Association (AMA) Annual Meeting voted in support of the 
WHO's designation of infertility as a disease. Despite this designation, insurance coverage for infertility treatment continues to be more the exception than the norm in many developed countries including the USA. In the public eye, assisted reproductive technology (ART) must contend with the image of being an elective luxury service. This perception lingers on today even though a large population survey in six European countries, the USA, and Australia found over two decades ago that the majority of interviewed individuals $(70 \%)$ in the general public felt that IVF should be reimbursable [5].

And while an increasing number of states in the USAcurrently nineteen - have enacted infertility mandates, gaps in implementation of the mandates and access to fertility services remain [6]. A survey from one such "mandated state," Massachusetts, found that the majority of individuals accessing infertility services were Caucasian, highly educated, and wealthy [7]. The authors of the study identified "glaring disparities" and speculated that the reasons for these were "unclear and likely multifactorial." Galic et al. reported very similar findings in Illinois, another "mandated state" [8]. In their cross-sectional survey of 1460 fertility care patients, three quarters were White, and the vast majority $(81.5 \%)$ reported an annual household income of $>\$ 100,000$. The investigators concluded that in addition to insurance considerations, "complex social, cultural, racial, and economic factors" represent a barrier to social justice and equity with regards to access to infertility care.

A recent qualitative systematic review sought to identify barriers to fertility care for racial/ethnic minority groups. Kirubaraja et al. identified several key barriers to equitable fertility care: "stigmatization of fertility care, lack of infertility knowledge, language barriers, discrimination, and lack of institutional trust" [9].

They outlined approaches to each of the identified factors, including diversification of the fertility provider workforce, multilingual provision of care, and screening for psychosocial services.

Beyond socio-economic and racial/ethnic factors, gender identity and sexual orientation have also been postulated to predispose to restricted fertility care access. While geographic variations exist, there is increasing acceptance of the provision of ART services for patients who differ from the heteronormative family, such as gay and lesbian patients [10]. However, transgender and nonbinary patients may experience reluctance and discomfort about the provision of fertility services, prompting the American Society of Reproductive Medicine (ASRM) to issue an Ethics Committee opinion on this topic [11]. The statement affirms that transgender and nonbinary patients should receive fertility preservation counseling services and access to ART and that there is no evidence of harm for children raised by transgender parents.

This brings us back to Maansi's mission: because she believes that healthcare is a basic human right that should be offered equitably to everyone, she created "Healing Word," a site dedicated to health equity. She is particularly vocal about healthcare disparities surrounding the LGBTQ+ community, pointing out that human rights should not be a political or partisan issue. It was refreshing to hear the perspective from someone who has not been worn down by the repetitive use of statements like "That's just the way it is" over the years. And even though, as an emancipated minor/young adult, she clearly is mature beyond her age, I was reminded of the German saying "Kindermund tut Wahrheit kund" ("The mouth of a child reveals the truth").

On her website, Maansi quotes Friedrich Nietzsche: "He who has a why to live for can bear almost any how." Let us remember the "why" we first decided to pursue a career in our field. By taking inspiration from Maansi's unblemished enthusiasm, we too can do our part to increase access to care for the disease of infertility.

\section{References}

1. Blumenthal D, Fowler EJ, Abrams M, Collins SR. Covid-19 - implications for the health care system. N Engl J Med. 2020;383(15): 1483-8.

2. Insogna IG, Ginsburg ES. Infertility, inequality, and how lack of insurance coverage compromises reproductive autonomy. AMA J Ethics. 2018;20(12):E1152-9.

3. Thakker S, Persily J, Voigt P, Blakemore J, Licciardi F, Najari BB. Evaluating the unevaluated: a secondary analysis of the National Survey for Family Growth (NSFG) examining infertile women who did not access care. J Assist Reprod Genet. 2021;20:1-6.

4. Adashi EY. Infertility: A Disease by Any Other Name. In: JAMA Health Forum 2018 Dec 19 (Vol. 7, No. 1). American Medical Association.

5. Adashi EY, Cohen J, Hamberger L, Jones HW Jr, de Kretser DM, Lunenfeld B, et al. Public perception on infertility and its treatment: an international survey. The Bertarelli Foundation Scientific Board. Hum Reprod. 2000;15(2):330-4.

6. Kawwass JF, Penzias AS, Adashi EY. Fertility-a human right worthy of mandated insurance coverage: the evolution, limitations, and future of access to care. Fertil Steril. 2021;115(1):29-42.

7. Jain T, Hornstein MD. Disparities in access to infertility services in a state with mandated insurance coverage. Fertil Steril. 2005;84(1): 221-3.

8. Galic I, Negris O, Warren C, Brown D, Bozen A, Jain T. Disparities in access to fertility care: who's in and who's out. F\&S Reports. 2021;2(1):109-17.

9. Kirubarajan A, Patel P, Leung S, Prethipan T, Sierra S. Barriers to fertility care for racial/ethnic minority groups: a qualitative systematic review. F\&S Reviews. 2021;2(2):150-9.

10. De Wert G, et al. ESHRE Task Force on Ethics and Law 23: medically assisted reproduction in singles, lesbian and gay couples, and transsexual peopledagger. Hum Reprod. 2014;29(9):1859-65.

11. Ethics Committee of the American Society for Reproductive Medicine. Access to fertility services by transgender and nonbinary persons: an Ethics Committee opinion. Fertil Steril. 2021;115(4): 874-878.

Publisher's note Springer Nature remains neutral with regard to jurisdictional claims in published maps and institutional affiliations. 